\title{
ELIMINATING THE CERVICAL ESOPHAGOGASTRIC ANASTOMOTIC LEAK WITH A SIDE-TO-SIDE STAPLED ANASTOMOSIS
}

Mark B. Orringer, MD

Becky Marshall

Mark D. Iannettoni, MD
Background: Although the acute postoperative complications of a cervical esophagogastric anastomosis are less than those with an intrathoracic esophageal anastomosis, the long-term sequelae of a cervical anastomotic leak are not as minor as initially reported. Nearly $50 \%$ of cervical anastomotic leaks result in an anastomotic stricture, and the subsequent need for chronic dilatations negates the merits of an operation intended to restore comfortable swallowing. Objective: This study was undertaken to determine whether construction of a side-to-side stapled cervical esophagogastric anastomosis after transhiatal esophagectomy could reliably eliminate the majority of anastomotic leaks. Methods: In 114 consecutive patients undergoing transhiatal esophagectomy, a functional side-to-side cervical esophagogastric anastomosis was constructed with the Auto Suture Endo-GIA II stapler (United States Surgical Corporation, Auto Suture Company Division, Norwalk, Conn) applied directly through the cervical wound. This side-to-side stapled anastomosis has 3 rows of staples. Early postoperative anastomotic morbidity, subsequent need for anastomotic dilatations, and patient satisfaction with swallowing were evaluated. Results: Before the side-to-side stapled anastomosis, the incidence of cervical esophagogastric anastomosis leak in over 1000 patients undergoing transhiatal esophagectomy having a manually sewn anastomosis varied from $10 \%$ to $15 \%$. Among the 111 survivors of transhiatal esophagectomy and a side-to-side stapled anastomosis, there were $3(2.7 \%)$ clinically significant anastomotic leaks. This lowered incidence of leaks has contributed to reduction in the average length of stay after an uncomplicated transhiatal esophagectomy to 7 days and has provided more comfortable swallowing, ease of subsequent esophageal dilatations, and greater patient satisfaction. Conclusions: Construction of the cervical esophagogastric anastomosis with a side-to-side stapled anastomosis greatly reduces the frequency of anastomotic leaks and later strictures. The side-to-side stapled anastomosis is a major technical advance in the progression of refinements of transhiatal esophagectomy and a cervical esophagogastric anastomosis. (J Thorac Cardiovasc Surg 2000;119:277-88)
W ith the rediscovery and popularization of the technique of transhiatal esophagectomy (THE) without thoracotomy, ${ }^{1}$ the cervical esophagogastric anastomosis (CEGA) has become an increasingly common

From the Section of General Thoracic Surgery, Department of Surgery, University of Michigan Medical School, Ann Arbor, Mich.

Read at the Seventy-ninth Annual Meeting of The American Association for Thoracic Surgery, New Orleans, La, April 18-21, 1999.

Received for publication April 22, 1999; revisions requested June 29, 1999; revisions received Oct 11, 1999; accepted for publication Oct $12,1999$. procedure. One advantage of this approach is that a CEGA leak is seldom associated with mediastinitis. Although more than $98 \%$ of CEGA leaks are relatively benign and managed successfully with local wound

Address for reprints: Mark B. Orringer, MD, Professor and Head, Section of General Thoracic Surgery, University of Michigan Medical Center, 1500 E. Medical Center Dr, 2120 Taubman Center, Box 0344, Ann Arbor, MI 48109 (E-mail: morrin@umich.edu).

Copyright $\odot 2000$ by Mosby, Inc.

$0022-5223 / 2000 \$ 12.00+0 \quad \mathbf{1 2 / 6 / 1 0 3 6 0 3}$ 


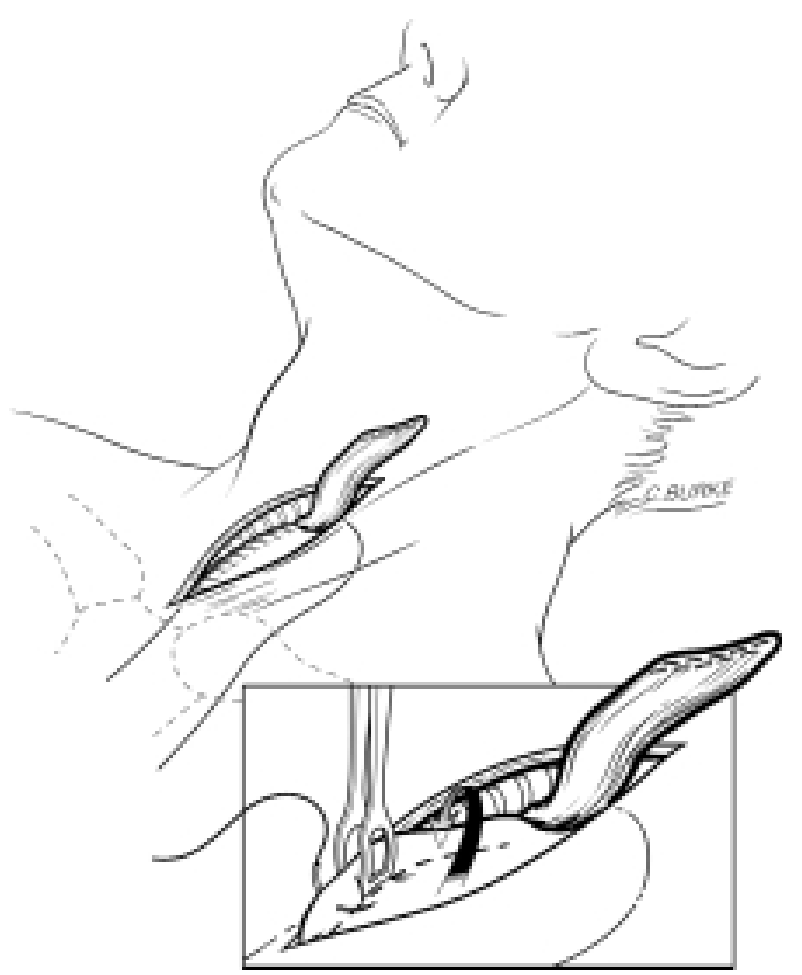

Fig 1. The tip of the properly mobilized stomach should rest 4 to $5 \mathrm{~cm}$ above the level of the clavicles along the prevertebral fascia, well behind the divided cervical esophagus, which is retracted superiorly with an Allis clamp (not shown). The oversewn gastric staple suture line along the lesser curvature side of the stomach is toward the patient's right. Inset, A Babcock clamp gently elevates the anterior surface of the gastric fundus into the field, rotating the staple suture line (dotted line) even more medially away from the future site of the anastomosis. A 3-0 cardiovascular traction suture placed distal to the clamp helps to elevate the stomach to the surface of the wound.

care, there is a small incidence of disastrous complications that may be associated with a CEGA. ${ }^{2}$ Furthermore, although the acute postoperative complications of a CEGA are clearly less than those associated with an intrathoracic esophagogastric anastomosis, the long-term sequelae of a cervical leak have not proven to be as minor as was initially thought to be the case. As many as $50 \%$ of cervical esophagogastric anastomotic leaks result in an anastomotic stricture, as fibrosis associated with healing becomes established. The subsequent need for chronic esophageal dilatations negates the merits of an operation intended to restore comfortable swallowing.

Despite a variety of attempts over the years to lower the incidence of CEGA leak by altering the technique

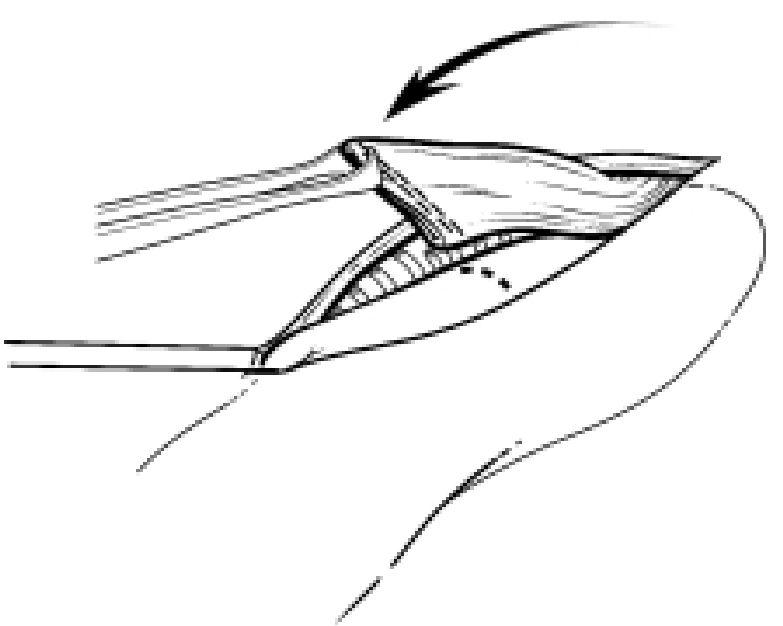

Fig 2. The site of the $1.5-\mathrm{cm}$ transverse gastrotomy is carefully selected with some planned redundancy in the length of the cervical esophagus, and therefore once the traction suture is removed and the stomach partially retracts downward into the thoracic inlet, there will not be undue tension on the anastomosis. The gastrotomy is performed with a needle-tip electrocautery.

of the manually sutured anastomosis, in the authors' experience the incidence of leak after a CEGA has varied between $10 \%$ and $15 \% .^{3}$ The Auto Suture EndoGIA II surgical stapling device (United States Surgical Corporation, Auto Suture Company Division, Norwalk, Conn) offers the advantages of a triple-layered suture line and ease of anastomotic construction directly through the cervical incision. This instrument has already demonstrated its utility in esophageal surgery in the repair of intrathoracic esophageal perforations. ${ }^{4}$ This study was undertaken to determine whether construction of a side-to-side stapled CEGA with the Auto Suture Endo-GIA II stapler could reliably eliminate the majority of anastomotic leaks after THE.

\section{Methods}

A total of 114 consecutive patients undergoing THE and esophageal replacement with the stomach positioned in the original esophageal bed between July 29, 1997, and January 19,1999 , underwent construction of a functional side-to-side CEGA with the Endo GIA II 30-3.5 stapler applied directly through the cervical wound. The postoperative courses of these patients were analyzed with particular reference to the incidence of anastomotic leaks, length of hospital stay, need for and ease of subsequent early postoperative anastomotic dilatations, and patient satisfaction with swallowing. These results were compared with data derived from a similar consecutive cohort of 114 patients undergoing THE having manually sewn CEGAs between June 4, 1996, and July 28, 1997, 


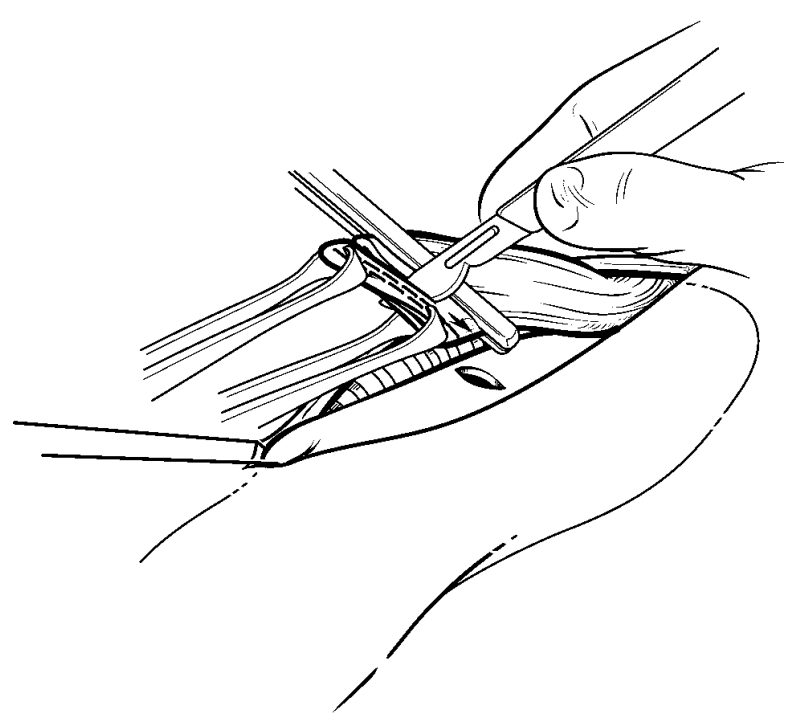

Fig 3. When dividing the cervical esophagus during a THE, the stapler is applied obliquely in an anterior-to-posterior orientation, with the anterior tip longer than the posterior tip. At the time of the anastomosis, this oblique division is maintained because an atraumatic vascular forceps is used as a guide for amputation of the staple suture line, which is submitted as the proximal esophageal margin.

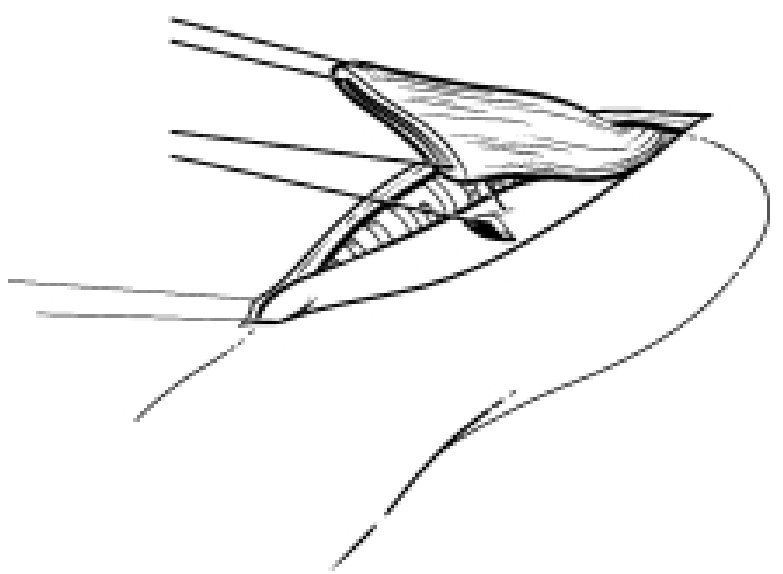

Fig 4. Two full-thickness anastomotic stay sutures of 4-0 polyglycolic acid are placed, one from the anterior tip of the cut cervical esophagus and one from the midpoint of the upper edge of the transverse gastrotomy and the posterior corner of the esophagus. The anterior gastric wall traction suture placed previously has been fixed to the drapes with a hemostat to facilitate construction of the anastomosis.

immediately preceding this current series of 114 patients with stapled anastomoses. Statistical comparison between the groups was performed by using 2-sided $\mathrm{z}$ tests for proportions with STATA 5.0 software (Stata Corporation, College
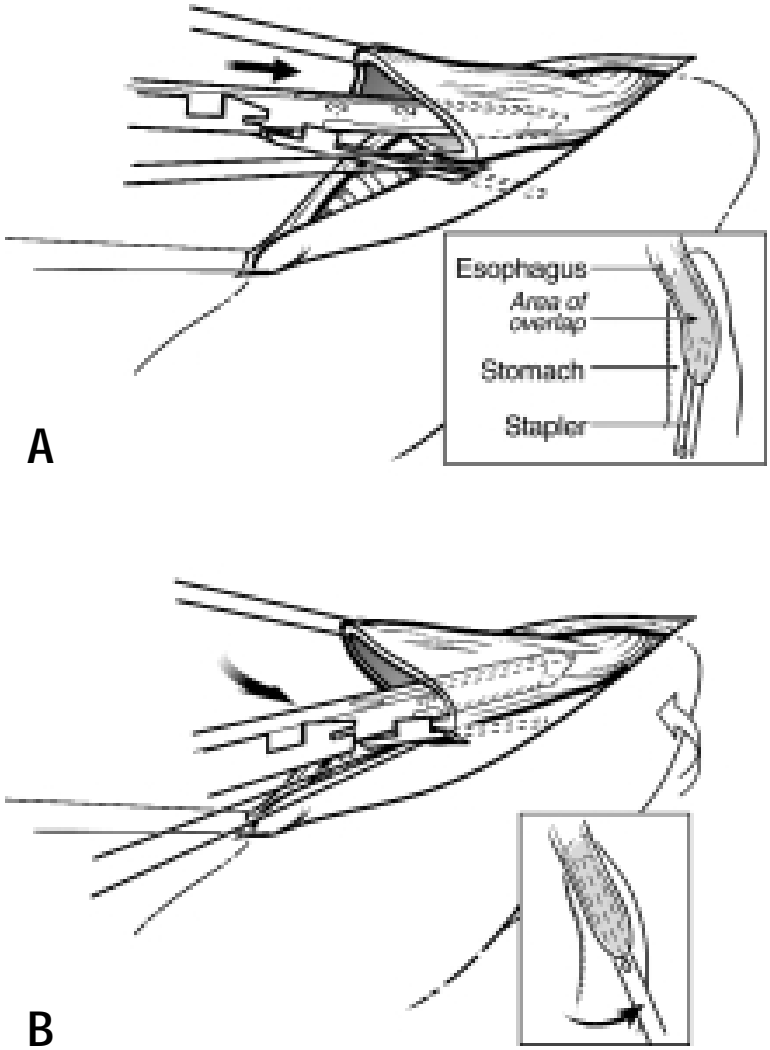

Fig 5. A, The two anastomotic stay sutures are retracted downward as the Endo-GIA 30-3.5 staple cartridge is inserted, the thinner anvil portion into the stomach and the thicker staple-bearing portion into the esophagus. B, As the staple cartridge is advanced completely into the esophagus and stomach, it is gradually rotated so that the tip is pointing toward the patient's right ear. Insets, The area of overlap of the esophagus is carefully planned so that the gastric staple suture line is well away from the anastomosis, and the alignment of the esophagus and stomach is parallel.

Station, Tex). A propensity score-adjusted analysis was used to verify these results. ${ }^{5,6}$

After the esophagectomy, the stomach is mobilized through the posterior mediastinum until 4 to $5 \mathrm{~cm}$ of gastric fundus rests above the level of the clavicles (Fig 1). A traction suture is used to elevate the anterior gastric wall into the field. A 1.5$\mathrm{cm}$ transverse gastrotomy is made on the anterior gastric wall (Fig 2). This gastrotomy must be placed far enough inferior to the tip of the gastric fundus to permit the subsequent full insertion of the $3-\mathrm{cm}$ long staple cartridge. Because the stomach will at least partially retract downward into the thoracic inlet once the traction suture is removed, there must be some redundancy in the length of the cervical esophagus as the anastomosis is constructed. The cervical esophageal suture line is amputated obliquely, with the anterior tip of the esophagus being slightly longer than the posterior corner (Fig 3). 

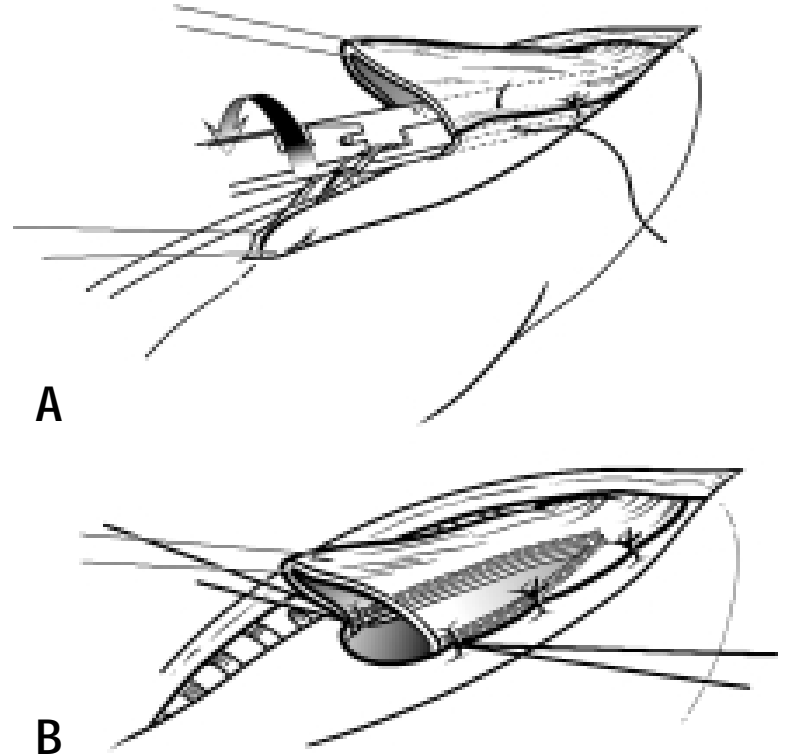

Fig 6. A, The handle of the stapler is squeezed, thereby approximating the jaws, but before firing it, the stapler is rolled from one side to the other as two suspension seromuscular sutures between the adjacent esophagus and stomach are placed on either side. B, The stapler is fired by advancing the knife assembly, and a 3-cm long side-to-side anastomosis is created as the common walls between the esophagus and stomach are cut. After removing the stapler, the anastomosis is inspected for bleeding, and a nasogastric tube is inserted. Corner sutures are placed in preparation for completion of the anastomosis.

Two anastomotic stay sutures are placed (Fig 4), and with downward traction on the stay sutures, the Auto Suture Endo GIA II 30-3.5 stapler cartridge loaded on a Versafire GIA stapler (Auto Suture Company) is inserted into the stomach and the esophagus (Fig 5, A). It is important to achieve alignment of the posterior wall of the cervical esophagus and the anterior wall of the stomach as the staple cartridge is advanced completely into the esophagus and stomach (Fig 5, B). After the stapler jaws are approximated, 2 suspension sutures between the anterior stomach and the adjacent posterior esophageal wall are placed on either side (Fig 6, A). A 3-cm long side-to-side anastomosis is performed by firing the stapler (Fig 6, B). A 16F nasogastric tube is inserted by the anesthetist and advanced downward into the intrathoracic stomach for postoperative gastric decompression. The gastrotomy and remaining open esophagus are then approximated (Fig 7).

\section{Results}

A large number of variables were used to compare these 2 groups of 114 patients undergoing THE and CEGA (stapled vs manually sewn). There was no statistically significant difference between the groups in

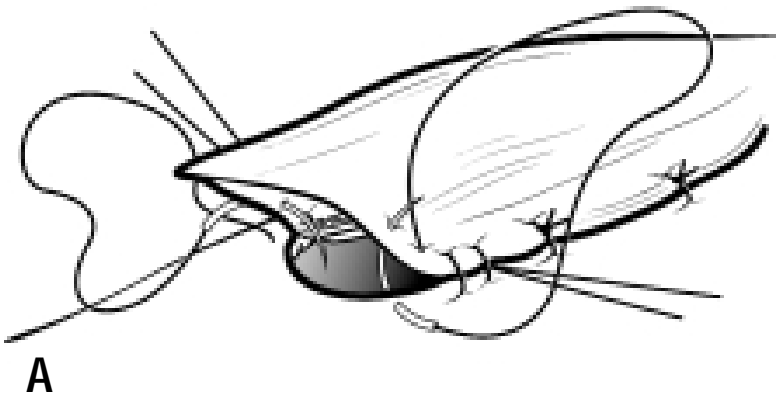

B

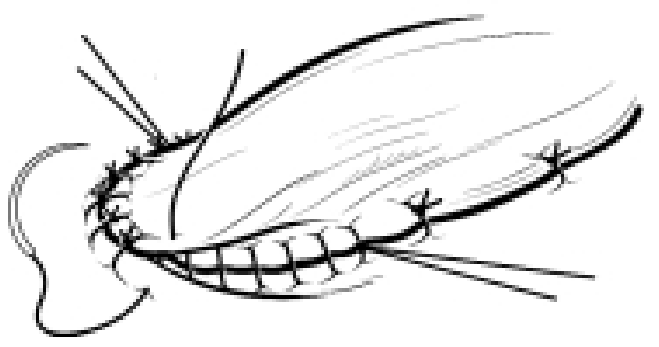

Fig 7. The gastrotomy and remaining open esophagus are closed in 2 layers: a running inner layer of 4-0 monofilament absorbable suture (A) and an outer interrupted layer that incorporates the anterior wall of the upper esophagus (B). This final anterior closure of the gastrotomy and esophagotomy is independent of the actual side-to-side anastomosis, which is contained within the hood of the overlying esophagus.

average age (62 vs 65 years), sex (78\% vs $73 \%$ men), proportion with carcinoma $(78 \%$ vs $77 \%)$, original weight, amount of weight loss, tumor histology, tumor site, proportion of patients with benign disease having prior esophageal operations (eg, a fundoplication), and proportion of patients with carcinoma having preoperative chemotherapy. The only significantly different variable was the proportion of patients receiving preoperative radiation therapy, with $32 \%$ of those having a manual anastomosis versus $49 \%$ of those with a stapled anastomosis $(P=.02)$. Clinically, however, although one would have expected the higher proportion of radiation therapy to result in more anastomotic leaks in the group with stapled anastomoses, this was not the case. To quantitatively assess this comparison, a propensity score-adjusted analysis was performed by using the covariates of age, sex, weight, whether the patient had cancer, tumor site, tumor histology, tumor stage, and whether the patient had preoperative chemotherapy and radiation therapy. 5,6 Two separate analyses were then conducted, one for all patients and one for patients with cancer (Table I). For all patients, the difference in the directly adjusted proportion of leaks between manual and stapled groups is 0.13 (SEM, 0.037; 95\% confi- 
Table I. Propensity score-adjusted comparison of manual versus stapled CEGAs

\begin{tabular}{|c|c|c|c|c|}
\hline$P S G$ & Treatment group & No. of patients & Proportion of leak & SEM \\
\hline \multicolumn{5}{|l|}{ All patients } \\
\hline \multirow[t]{2}{*}{1} & Manual & 29 & 0.034 & 0.03 \\
\hline & Stapled & 14 & 0 & 0 \\
\hline \multirow[t]{2}{*}{2} & Manual & 20 & 0.250 & 0.10 \\
\hline & Stapled & 22 & 0.045 & 0.04 \\
\hline \multirow[t]{2}{*}{3} & Manual & 26 & 0.077 & 0.05 \\
\hline & Stapled & 24 & 0.042 & 0.04 \\
\hline \multirow[t]{2}{*}{4} & Manual & 19 & 0.316 & 0.11 \\
\hline & Stapled & 28 & 0.036 & 0.04 \\
\hline \multirow[t]{2}{*}{5} & Manual & 20 & 0.100 & 0.07 \\
\hline & Stapled & 26 & 0 & 0 \\
\hline Directly adjusted & Manual & - & 0.155 & 0.034 \\
\hline Across PSGs & Stapled & - & 0.025 & 0.014 \\
\hline \multicolumn{5}{|c|}{ Patients with cancer } \\
\hline \multirow[t]{2}{*}{1} & Manual & 27 & 0.037 & 0.04 \\
\hline & Stapled & 8 & 0 & 0 \\
\hline \multirow[t]{2}{*}{2} & Manual & 18 & 0.167 & 0.09 \\
\hline & Stapled & 17 & 0.059 & 0.06 \\
\hline \multirow[t]{2}{*}{3} & Manual & 20 & 0.050 & 0.05 \\
\hline & Stapled & 16 & 0 & 0 \\
\hline \multirow[t]{2}{*}{4} & Manual & 12 & 0.167 & 0.11 \\
\hline & Stapled & 23 & 0.043 & 0.04 \\
\hline \multirow[t]{2}{*}{5} & Manual & 11 & 0.182 & 0.12 \\
\hline & Stapled & 25 & 0 & 0 \\
\hline Directly adjusted & Manual & - & 0.120 & 0.038 \\
\hline Across PSGs & Stapled & - & 0.020 & 0.014 \\
\hline
\end{tabular}

$P S G$, Propensity score group.

dence interval, 0.057-0.203). This indicates that the proportion of leaks is significantly higher for the manual sewn anastomosis group than the stapled anastomosis group after adjusting by the propensity score $(P$ $<.001)$. For those patients with cancer, the difference in the directly adjusted proportion of leaks between manual sewn and stapled anastomosis groups is 0.10 (SEM, 0.041; 95\% confidence interval, 0.020-0.18). This indicates that the proportion of leaks is significantly higher for the manually sewn anastomosis group than the stapled anastomosis group after adjusting by the propensity score $(P=.014)$. (A full report of the propensity score analysis is available upon request from the senior author, Dr Orringer.) These results are the basis for our belief that the difference in anastomotic leak rates between these 2 groups was due to the type of CEGA they had (manually sewn or stapled) and not to other patient characteristics.

Among the patients with stapled anastomoses, there were 3 hospital deaths (2.6\%) from pulmonary complications: respiratory insufficiency (2) and aspiration pneumonia (1). Nine of the 111 operative survivors had their cervical wounds opened early after their esophagectomy for a suspected or documented anasto- motic leak. However, clinically significant true anastomotic leaks (fistulas) requiring treatment occurred in only 3 of these patients (2.7\%; Table II). Patient 1 was discharged after an uneventful course on postoperative day 7 and 4 days later experienced epigastric pain while eating. A repeat barium swallow showed a cervical anastomotic leak that drained into the right side of the chest. A chest tube was placed, and the neck wound was opened and packed. Irrigations with swallowed water were carried out thereafter. The fistula closed 17 days later. Patients 1, 2, and 3 had their operations early in our experience with the stapled anastomosis. None of them had lateral suspension sutures on either side of the anastomosis, as shown in Fig 6, and 2 of the 3 had only a single-layer running closure of the esophagus and gastrotomy rather than the double-layered closure shown in Fig 7. Two of the 3 had also received preoperative chemoradiation of distal third adenocarcinomas.

Patient 4 had an asymptomatic "small contained anastomotic leak" detected on her routine postoperative barium swallow. She required no treatment for this. Patients 5 and 6 had false positive postoperative barium swallow results. Their neck wounds were opened at the bedside and packed on the suspicion of gastric necro- 
Table II. Cervical wound problems after THE and stapled side-to-side anastomosis

\begin{tabular}{|c|c|c|}
\hline $\begin{array}{l}\text { Indication for } \\
\text { opening wound }\end{array}$ & Indication for $T H E$ & Presentation \\
\hline \multicolumn{3}{|c|}{$\begin{array}{l}\text { Clinically significant } \\
\text { anastomotic leak (fistula) }\end{array}$} \\
\hline Patient 1 & $\begin{array}{l}\text { Adenocarcinoma-cardia } \\
\mathrm{s} / \mathrm{p} \text { chemoradiation }\end{array}$ & Leak draining into right side of chest on $\mathrm{BaS}-\mathrm{POD} 11$ \\
\hline Patient 2 & $\begin{array}{l}\text { Distal one third adenocarcinoma } \\
\mathrm{s} / \mathrm{p} \text { chemoradiation }\end{array}$ & Fever and purulent drainage from neck wound-POD 12 \\
\hline Patient 3 & Distal one third adenocarcinoma & Foul drainage from neck wound-POD 7 \\
\hline \multicolumn{3}{|c|}{$\begin{array}{l}\text { Equivocal } \\
\text { anastomotic problems }\end{array}$} \\
\hline Patient 4 & Failed antireflux operation; dysmotility & Asymptomatic small contained leak on BaS-POD 11 \\
\hline Patient 5 & $\begin{array}{l}\text { Distal one third squamous cell } \\
\text { carcinoma s/p chemoradiation }\end{array}$ & Low-grade fever and odor and equivocal BaS-POD 5 \\
\hline Patient 6 & $\begin{array}{l}\text { Adenocarcinoma-cardia } \\
\mathrm{s} / \mathrm{p} \text { chemoradiation }\end{array}$ & Low-grade fever and odor and equivocal BaS-POD 5 \\
\hline Patient 7 & $\begin{array}{l}\text { Adenocarcinoma-cardia } \\
\mathrm{s} / \mathrm{p} \text { chemoradiation }\end{array}$ & $\begin{array}{l}\text { Cervical subcutaneous emphysema while retching-POD 5; } \\
\text { BaS negative }\end{array}$ \\
\hline \multicolumn{3}{|c|}{ Gastric tip necrosis } \\
\hline Patient 8 & Adenocarcinoma—cardia & Purulent neck wound drainage and odor-POD 4 \\
\hline Patient 9 & $\begin{array}{l}\text { High-grade dysplasia/stage I } \\
\text { adenocarcinoma in Barrett's mucosa }\end{array}$ & Purulent neck wound drainage_-POD 6; BaS negative \\
\hline Patient 10 & $\begin{array}{l}\text { Distal one third adenocarcinoma } \\
\mathrm{s} / \mathrm{p} \text { chemoradiation }\end{array}$ & $\begin{array}{l}\text { Cervical subcutaneous air during severe coughing at home- } \\
\text { POD 26; BaS-leak }\end{array}$ \\
\hline
\end{tabular}

$s / p$, Status post; $P O D$, postoperative day; $B a S$, barium swallow.

sis, but anastomotic leaks were never documented by drainage from the wound of swallowed esophageal contents, and they did well. Patient 7, a 126-kg man, retched while receiving jejunostomy tube feedings on postoperative day 5 and had cervical subcutaneous air. The neck wound was opened at the bedside, but no anastomotic leak was ever documented.

Three patients experienced variations of gastric tip necrosis. In patient 8 exploration of the neck wound in the operating room revealed that the upper $5 \mathrm{~cm}$ of stomach above the thoracic inlet were necrotic; the anastomosis was intact. Patient 9 was a $105-\mathrm{kg}$ man who, on exploration of the neck wound, was found to have gastric tip necrosis and an intact anastomosis. When the abdomen was reopened to deliver the stomach out of the mediastinum, there was edema and narrowing at the diaphragmatic hiatus that had compressed the right gastroepiploic vascular pedicle. The upper half of the intrathoracic stomach, not just the portion in the neck, was ischemic and resected. Patient 10 was a cachectic man with severe chronic obstructive pulmonary disease. He was discharged on day 8 after a rel- atively uneventful THE. Eighteen days later, on postoperative day 26 , during a bout of severe coughing, cervical subcutaneous air developed. A barium swallow showed a small anastomotic leak. The neck wound was opened at the bedside and packed. Necrotic gastric tissue was debrided from the wound over the next several days, but endoscopy revealed continuity between the esophagus and stomach. Wound packing was continued, and he was discharged 9 days later. He died 2 months later of progressive cachexia; the cervical fistula never healed completely.

Twenty patients experienced a variety of nonanastomotic-related complications prolonging the hospital stay beyond 10 days. Among the 111 survivors of the operation, 91 (82\%) had either completely uncomplicated postoperative courses or minor complications (eg, urinary tract infection, transient atrial fibrillation, and superficial wound infection) that did not prolong their hospitalization beyond 10 days. Of the 91 patients with stapled anastomoses undergoing uncomplicated THE, $79(87 \%)$ had a postoperative length of stay of 8 days or less (Table III). 
Neck wound opened at bedside and packed; chest tube; swallowed water irrigation of chest

Neck wound opened at bedside and packed

Neck wound opened at bedside and packed

None

Neck wound opened at bedside and packed

Neck wound opened at bedside and packed

Neck wound opened at bedside and packed

Neck wound opened at bedside — no leak; wound explored in operating room for persistent purulence-gastric tip necrosis, anastomosis intact-stomach taken down, necrosis resected, cervical esophagostomy

Neck wound opened at bedside — no leak; wound explored in operating room for persistent fever and drainage-necrosis of upper half of stomach, anastomosis intact - resection of necrotic stomach, cervical esophagostomy

Neck wound opened at bedside and packed; necrotic gastric tissue debrided
Leak closed in 17 days

Leak closed in 13 days

Leak closed in 22 days

No difficulty with anastomosis

No leak documented, wound healed

No leak documented, wound healed

No leak documented, wound healed

Successful substernal colon interposition after 6 months

Successful substernal colon interposition after 7 months

Discharged packing wound after 9 days; died 2 months later from progressive cancer; fistula persisted
In contrast with the stapled anastomosis group, in which clinically documented anastomotic leaks occurred in $3(2.7 \%)$ of the 111 operative survivors, in the manually sewn anastomotic group anastomotic leaks requiring opening the neck wound and packing occurred in $16(14 \%)$ of the 112 operative survivors $(P$ $=.0019 ;$ Table IV). Fifteen of these 16 patients had overt clinical evidence of an anastomotic leak (ie, fever and drainage from the neck wound occurring between 4 and 13 days after the THE). One was found to have a large contained asymptomatic leak on a routine barium swallow on day 19. In each case the wound was opened at the bedside, it was confirmed that a true fistula was present because swallowed water issued from the wound, and packing was instituted. There were no false positive barium swallow examination results in this group or neck wounds that were opened on the suspicion of a leak that could not then be demonstrated. Gastric tip necrosis did not occur in this group of patients. Among the 112 operative survivors in the manually sewn anastomosis group, 77 (69\%) had either completely uncomplicated postoperative courses or minor complications that did not prolong their hospital stay beyond 10 days. Of these 77 patients undergoing uncomplicated THE, 33 (43\%) were discharged within 8 days or less after surgery (Table III; $P=.0001$ ).

Since our early experience with THE and a CEGA, we have performed outpatient anastomotic dilatations with $46 \mathrm{~F}$ or larger esophageal bougies for any postoperative complaint of cervical dysphagia. With this liberal policy of anastomotic dilatation, $48 \%$ of the patients with a manually sewn anastomosis have required one or more outpatient anastomotic dilatations within the first 3 months of operation versus $35 \%$ of patients undergoing a stapled anastomosis $(P=.05$; Table V). Although nearly equal numbers have had a single dilatation (24\% vs $23 \%$ ), $24 \%$ of the patients with manually sewn anastomoses have required 2 or more anastomotic dilations versus $12 \%$ of those with stapled anastomoses $(P=.02)$. It has also been noted by the authors that negotiating the stapled CEGA with a large-caliber dilator has been easier than doing so with our previous manually sewn anastomoses. Patients have expressed greater satisfaction with their 
Table III. Length of stay after uncomplicated THE and CEGA

\begin{tabular}{lcc}
\hline Length of stay & $\begin{array}{c}\text { No. of patients } \\
\text { with manually sewn } \\
\text { anastomoses } \\
(n=77)\end{array}$ & $\begin{array}{c}\text { No. of patients } \\
\text { with stapled } \\
\text { anastomoses } \\
(n=91)\end{array}$ \\
\hline 11 & 5 & 1 \\
10 & 22 & 5 \\
9 & 17 & 6 \\
8 & 16 & 32 \\
7 & 16 & 36 \\
6 & 1 & 9 \\
5 & - & 2 \\
\hline
\end{tabular}

Forty-three percent of patients having a manually sewn anastomosis had a length of stay of 5 to 8 days versus $87 \%$ of patients with a stapled anastomosis. $P=.0001$ for difference in proportions. Uncomplicated indicates either no complications or minor complications not prolonging hospitalization for greater than 10 days.

Table IV. Comparison of cervical wound problems after CEGA

\begin{tabular}{lll}
\hline & $\begin{array}{c}\text { Manually sewn } \\
\text { anastomosis } \\
(112 \text { operative } \\
\text { survivors })\end{array}$ & $\begin{array}{c}\text { Stapled } \\
\text { anastomosis } \\
(111 \text { operative } \\
\text { survivors })\end{array}$ \\
\hline $\begin{array}{l}\text { Anastomotic leak: wound opened } \\
\text { and packed }\end{array}$ & $16(14 \%)$ & $3(2.7 \%)^{*}$ \\
$\begin{array}{l}\text { Contained leak on BaS: } \\
\text { no treatment }\end{array}$ & 0 & 1 \\
$\begin{array}{l}\text { Equivocal BaS: wound opened, } \\
\text { no leak }\end{array}$ & 0 & 2 \\
$\begin{array}{l}\text { Cervical subcutaneous air while } \\
\text { coughing: wound opened, no leak }\end{array}$ & 0 & 1 \\
$\begin{array}{l}\text { Gastric tip necrosis } \\
\text { No leak; cervical esophagostomy } \\
\text { and gastrectomy required }\end{array}$ & 0 & 3 \\
$\begin{array}{l}\text { Late necrosis managed with } \\
\text { wound packing }\end{array}$ & 0 & 2 \\
\hline $\begin{array}{l}\text { BaS, Barium swallow. } \\
* P \text {. } 0019 .\end{array}$ & & 1 \\
\hline
\end{tabular}

ability to swallow comfortably, as reflected by the decreased need for multiple anastomotic dilatations in the first 3 months after THE.

\section{Discussion}

An esophageal anastomotic leak is among the leading causes of perioperative morbidity and mortality after an esophagectomy. Although there have been several recent outstanding reports documenting leak rates of less than $5 \%$, among 46,692 patients reported in the collective review by Muller and associates, ${ }^{7}$ the mean incidence of leakage after gastric replacement of the
Table V. Comparison of frequency of anastomotic dilatations in first 3 months after THE and either manually sewn or stapled anastomosis

\begin{tabular}{|c|c|c|}
\hline & \multicolumn{2}{|c|}{$\begin{array}{l}\text { No. of patients } \\
\text { requiring one or more dilatations }\end{array}$} \\
\hline & $\begin{array}{c}\text { Manually sewn } \\
\text { anastomosis } \\
\text { (54 of } 112 \text { patients) }\end{array}$ & $\begin{array}{c}\text { Stapled } \\
\text { anastomosis } \\
\text { (39 of } 111 \text { patients) }\end{array}$ \\
\hline \multicolumn{3}{|c|}{$\begin{array}{l}\text { Total No. of dilatations } \\
\text { in first } 3 \text { months }\end{array}$} \\
\hline 1 & $27(24 \%)$ & $26(23 \%)$ \\
\hline 2 & 13 & 6 \\
\hline 3 & 7 & 5 \\
\hline 4 & 3 & 1 \\
\hline 5 & 3 & 1 \\
\hline 9 & 1 & - \\
\hline Total & $54(48 \%)$ & $39(35 \%)$ \\
\hline
\end{tabular}

Twenty-four percent of patients having a manually sewn anastomosis underwent $2,3,4,5$, or 9 dilatations in the first 3 months versus $12 \%$ of patents having a stapled anastomosis. $P=.02$ for difference in proportions.

esophagus and an intrathoracic anastomosis was similar with either a 1-layer (12\%) or 2-layer (12\%) anastomosis and whether the anastomosis was performed manually $(11 \%)$ or with an EEA surgical stapler (United States Surgical Corporation, 13\%). Fok and associates ${ }^{8}$ compared a single-layer running manual anastomosis with a circular stapled technique in $\mathbf{5 8 0}$ esophageal anastomoses and reported an incidence of anastomotic leak in the manually sewn group of 5\% versus $3.8 \%$ in the stapled group $(P=.69)$; however, a greater number of stapled anastomoses resulted in strictures.

In a collective review of complications of THE (1353 patients), Katariya and associates ${ }^{9}$ reported a mean incidence of cervical anastomotic leak of $15 \%$, and the same number $(15 \%)$ had subsequent anastomotic strictures. The majority of these published series, however, represented the authors' initial experience with THE, as the average number of patients reported in the 23 papers reviewed was 59; in $16(70 \%)$ papers the authors' experience was with 50 patients or less. Dewar and associates ${ }^{10}$ reviewed 169 patients undergoing a CEGA after esophagogastrectomy and gastric tube interposition for cancer and reported a $17 \%$ incidence of anastomotic leak and a $31 \%$ incidence of anastomotic stricture, the later correlating with a preceding anastomotic leak $(P=.001)$. In their recent review of the complications of THE, Gandhi and Naunheim ${ }^{11}$ reported an incidence of anastomotic leak ranging from $5 \%$ to $26 \%$ and indicate that $10 \%$ to $15 \%$ of patients have benign anastomotic strictures after a CEGA. The 
Mayo Clinic group has reported a $25 \%$ incidence of cervical leak in 131 patients undergoing THE for carcinoma of the esophagus. ${ }^{12}$ Leaks occurred in $8(26 \%)$ of 31 stapled anastomoses and in 24 of 99 manually sutured anastomoses (24\%, $P=$ not significant). In the University of Michigan's experience with more than 1000 THEs and manually sewn CEGAs, regardless of the anastomotic technique (running, interrupted, single layered, or double layered), the incidence of anastomotic leak has remained between $10 \%$ and $15 \%$ (average, $13 \%)$.

Frustration with cervical esophageal anastomotic leaks has generated considerable investigation. Jacobi and associates ${ }^{13}$ have recorded progressively diminishing gastric submucosal tissue oxygen tension with each step of gastric mobilization: ligation of the short gastric and gastroepiploic vessels, ligation of the left gastric artery, and pull-up of the gastric tube. Several authors have proposed a variety of gastric tubes to maximize blood flow within the gastric esophageal substitute, thereby reducing the anastomotic leak rate. ${ }^{10,14}$ However, we agree with Collard and associates, ${ }^{15}$ Bardini and associates, ${ }^{16}$ and Akiyama ${ }^{17}$ that when replacing the esophagus with stomach, in order to preserve submucosal collateral circulation, as much of the stomach as possible should be retained rather than creating a gastric tube.

Although our initial focus was on the technique of THE, in recent years, this has shifted to methods of minimizing trauma to the mobilized stomach and particularly the gastric tip, which will be anastomosed to the cervical esophagus. Traction sutures in the tip of the stomach and suction devices to pull it through the posterior mediastinum and into the neck wound are now avoided. Rather, the mobilized stomach is gently manipulated upward through the diaphragmatic hiatus, beneath the aortic arch, and into the superior mediastinum by one hand until the tip of the gastric fundus can be grasped gently with a Babcock clamp inserted through the cervical incision and then the fingertips (Fig 8). The suspension sutures between the tip of the stomach and the cervical prevertebral fascia, as previously described, have been replaced by the less-traumatic lateral sutures between the esophagus and stomach placed once the stapler is in position (Fig 6, A).

In 1984 , Steichen ${ }^{18}$ reviewed the varieties of stapled esophageal anastomoses available at the time. He suggested use of a GIA stapler for construction of an endto-side esophagogastrostomy either in the chest or the low neck in a fashion similar to that described in this report with the Endo-GIA stapler. This technique, however, did not gain widespread popularity. Similarly, the EEA circular stapler has proven to be awkward and not

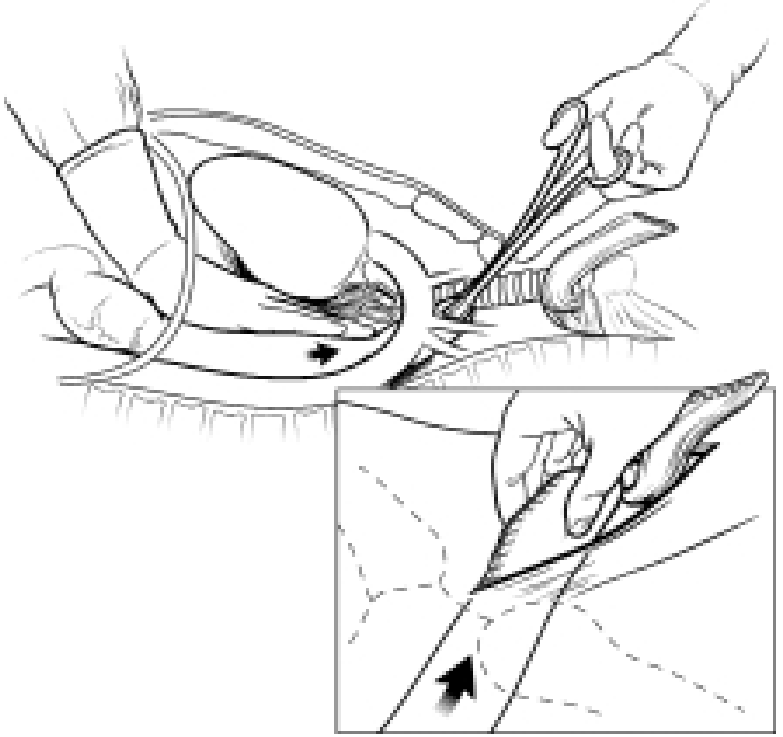

Fig 8. Positioning of the mobilized stomach through the posterior mediastinum in the original esophageal bed is done manually, with one hand inserted through the hiatus. This hand, kept flat and posteriorly to minimize cardiac displacement, gently pushes the stomach upward against the spine and beneath the aortic arch until the tip of the gastric fundus can be palpated by the fingers of the other hand inserted through the cervical incision. A Babcock clamp inserted through the cervical incision is used to deliver the gastric fundus into the neck wound until it can be grasped by the finger tips (inset). The clamp is not ratcheted closed completely to avoid trauma to the stomach. Four to five centimeters of stomach are delivered into the neck wound more by pushing from below in the chest rather than pulling from above in the neck.

well suited for construction of a cervical esophageal anastomosis. Collard and associates ${ }^{19}$ have described a side-to-side staple technique for construction of the CEGA by using the smaller and easier to use Endo-GIA stapler in 16 patients. Their cervical anastomosis is performed at the very tip of the mobilized stomach and in effect creates a functional end-to-end esophagogastric connection. It is our impression that subsequent gastroesophageal reflux is minimized if the end of the cervical esophagus is anastomosed to the anterior gastric wall in the neck several centimeters below the tip of the stomach as an end-to-side anastomosis. This results in a short retroesophageal gastric pouch, which can distend with air and at least in part minimize gastroesophageal reflux. For this reason, since our initial use of the CEGA after THE, we have consistently performed an end-toside esophagogastric anastomosis, and we have observed little clinically significant gastroesophageal reflux in late follow-up of these patients. 
The described side-to-side stapled CEGA has clear advantage over a mechanical anastomosis with the circular EEA stapler, which has not proved to be readily adaptable to a cervical anastomosis. It is simpler and requires no oral or retrograde gastric insertion of the instrument. A generous $3-\mathrm{cm}$ long anastomosis is less likely to stricture and more likely to provide comfortable swallowing. Although the final anterior closure of the anastomotic site (Fig 7) is hand sewn, this closure of the gastrotomy and esophagotomy is independent of the actual side-to-side anastomosis (Fig 6, $B$ ), which is contained within the hood of the overlying esophagus. This anterior closure can be done with relatively large bites of closely spaced inverting sutures and little concern about narrowing the anastomosis. Leakage from this site of closure is uncommon. Anastomotic leakage is less because the triple-layered staple construction provided by the ENDO-GIA II cartridge is apparently less traumatic and more water-tight than either a singleor double-layered hand-sewn anastomosis.

The disastrous complication of gastric tip necrosis after a CEGA is rare and has occurred in $11(1 \%)$ of our patients of more than 1000 undergoing THE. ${ }^{2}$ Gastric tip necrosis is generally a function of impaired gastric blood supply, whether from constriction of the stomach at either the thoracic inlet or the diaphragmatic hiatus, radiation effect on the gastric fundus, or multiple prior operations, such as fundoplication, and not the actual technique of anastomotic construction per se. In fact, the anastomosis may be intact when the diagnosis is made on exploration of the cervical wound, as was the case in patients 8 and 9 . In constructing the side-to-side stapled anastomosis, however, it is important that the gastric staple suture line along the lesser curvature be rolled medially away from the anterior surface of the gastric fundus, where the cervical anastomosis will be constructed. Inadvertent infringement of the anastomotic staple suture line on the lesser curvature gastric staple suture line may result in necrosis of the intervening gastric wall and a major problem with anastomotic healing, which may have occurred with the unusual delayed cervical fistula in patient 10 .

The greater reliability of the side-to-side stapled CEGA, with its $2.7 \%$ incidence of clinically significant leak, has been a major factor in reducing the postoperative length of stay of our patients. Oral intake of liquids is begun on the third postoperative day after the nasogastric tube is removed, and it is advanced to a mechanical soft diet by the seventh day when a barium swallow is obtained. If this shows no leak or other significant abnormality, the patient is discharged. For years, we have we insisted that our patients completely abstain from cigarette smoking for 2 to 3 weeks before operation, use an incentive inspirometer preoperatively, and walk 1 to 2 miles a day when possible to condition themselves for early postoperative ambulation. This, combined with the current use of postoperative epidural anesthesia to facilitate deep breathing, has allowed us to extubate our patients undergoing THE in the operating room and avoid intensive care and postoperative mechanical ventilation entirely. All of our patients are admitted for THE on the day of the operation. The trend toward discharge of our patients undergoing THE earlier than postoperative day 10 had already begun before we adopted the stapled anastomosis (Table III). Because up to $35 \%$ of our anastomotic leaks with the previously used hand-sewn anastomoses occurred between day 7 and 10 after surgery, the 10-day postoperative barium swallow was previously our gold standard used to clear the patient for discharge. With so few patients with the stapled anastomosis experiencing a postoperative leak, there is little justification now for keeping hospitalized a patient who has recovered from his esophagectomy and is otherwise ready for discharge within 5 to 7 days. A barium swallow is obtained as a quality control before discharge to avoid missing an occult anastomotic leak. This practice of an earlier barium swallow and discharge in patients with a stapled anastomosis is a function of the absolute decreased incidence of anastomotic leak in this group and not the current medical economic pressure for earlier discharge. Our experience with this anastomotic technique has increased our comfort level with earlier discharges, resulting in decreased length of stay for our patients and lowered hospital cost for esophagectomy. The side-to-side stapled CEGA is a major advance in the technical refinements of THE, which have occurred over the past 2 decades.

We thank Seema S. Sonnad, PhD, Assistant Professor, Department of Surgery, University of Michigan and Associate Director, Consortium for Health Outcomes, Innovation, and Cost Effectiveness Studies, who provided statistical consultation for this manuscript.

\section{REFERENCES}

1. Orringer MB, Sloan H. Esophagectomy without thoracotomy. J Thorac Cardiovasc Surg 1978;76:643-54.

2. Iannettoni MD, Whyte RI, Orringer MB. Catastrophic complications of the cervical esophagogastric anastomosis. J Thorac Cardiovasc Surg 1995;110:1493-501.

3. Orringer MB, Marshall B, Iannettoni MD. Transhiatal esophagectomy (THE) — clinical experience and refinements. Ann Surg 1999;230:392-400.

4. Whyte RI, Iannettoni MD, Orringer MB. Intrathoracic esopha- 
geal perforation: the merit of primary repair. J Thorac Cardiovasc Surg 1995;109:140-6.

5. Rosenbaum PR. Observational studies. New York: SpringerVerlag; 1995.

6. Rosenbaum PR, Rubin DB. Reducing bias in observational studies using subclassification on the propensity score. J Am Stat Assoc 1984;79:516-24.

7. Muller JM, Erasmi H, Stelzner M, Zieren U, Pichlmaier H. Surgical therapy of esophageal carcinoma. Br J Surg 1990;77: 845-57.

8. Fox M, Ah-Chong AK, Cheng SWK, Wong J. Comparison of a single layer continuous hand-sewn method and circular stapling in 580 esophageal anastomoses. Br J Surg 1991;78:342-5.

9. Katariya K, Harvey JC, Pina E, Beattle EJ. Complications of transhiatal esophagectomy. J Surg Oncol 1994;57:157-63.

10. Dewar L, Gelfand G, Finley RJ, Evans K, Inculet R, Nelems B. Factors affecting cervical anastomotic leak and stricture formation following esophagogastrectomy and gastric tube interposition. Am J Surg 1992;163:484-9.

11. Gandhi SK, Naunheim K. Complications of transhiatal esophagectomy. Chest Surg Clin North Am 1997;7:601-10.

12. Vigneswaran WT, Trastek VF, Pairolero PC, Deschamps C, Daly RC, Allen MS. Transhiatal esophagectomy for carcinoma of the esophagus. Ann Thorac Surg 1993;56:838-46.

13. Jacobi CA, Zieren HU, Zieren J, Muller JM. Is tissue oxygen tension during esophagectomy a predictor of esophagogastric anastomotic healing? J Surg Res 1998;74:161-4.

14. Schilling M, Redaelli C, Zbaren P, Baer HU, Seiler C, Friess H, et al. The clinical experience with fundus rotation gastroplasty as a substitute for the esophagus. Br J Surg 1997;84:126-8.

15. Collard JM, Tinton N, Malaise J, Romagnoli R, Otte JB, Kestens PJ. Esophageal replacement: Gastric tube or whole stomach? Ann Thorac Surg 1995;60:261-7.

16. Bardini R, Bonavina L, Asolati M, Ruol A, Castoro C, Tiso E. Single-layer cervical esophageal anastomoses: a prospective study of two suturing techniques. Ann Thorac Surg 1994;58: 1087-90.

17. Akiyama $\mathrm{H}$. Invited commentary on Bardini $\mathrm{R}$, Bonavina $\mathrm{L}$, Asolati M, Ruol A, Castoro C, Tiso E. Single-layer cervical esophageal anastomoses: a prospective study of two suturing techniques. Ann Thorac Surg 1994;58:1087-90.

18. Steichen FM. Varieties of stapled anastomoses of the esophagus. Surg Clin North Am 1984;64:481-98.

19. Collard JM, Romangnoli R, Goncette L, Otte JB, Kestens PJ. Terminalized semi-mechanical side-to-side suture technique for cervical esophagogastrostomy. Ann Thorac Surg 1998;65:814-7.

\section{Discussion}

Dr Victor Trastek (Rochester, Minn). The risks of esophageal resection historically have been high. Fortunately, regardless of the type of resection used today, these risks have come down over time. Dr Orringer has promoted the THE for most benign and malignant disease. Although initially there were many skeptics, through his persistence and continued accurate reporting of his results, he has confirmed the usefulness of this operation. And though we may differ on when to use it, it certainly has become part of the armamentarium of every general thoracic surgeon.

More important, and to Dr Orringer's credit, he has contin- ually perfected the operation and kept us informed of these improvements. This presentation is another in a long list of these improvements and discusses the cervical esophageal leak and a change in the anastomotic technique from a purely hand-sewn anastomosis to a stapled and partially handsewn anastomosis.

With this change in technique, his anastomotic leak rate has dropped from approximately $12 \%$ to $13 \%$ to $2.6 \%$, although I must say there were 3 patients who had gastric tip necrosis, and 4 did have an exploration of the neck for suspected leak. Postoperative dilations were decreased, as was stenosis, although $35 \%$ of the patients still did receive at least one dilation. The operative mortality rate was $2.6 \%$, which is in keeping with past reports, and his hospital stay has slowly been reduced to about 7 days. Although I prefer an Ivor Lewis technique for similar types of problems, and the mortality rate, leak rate, and stenosis are similar, the operative length of stay still remains 11 to 12 days.

I have 3 questions. First, could you shed some light on why the cervical anastomosis tends to leak at a higher rate? We have never been able to get the cervical leak rate down to the leak rate of the thoracic anastomosis, and indeed, as you know, our leak rate in the neck was higher than yours to begin with. If you can shed some light on this puzzle, how did your anastomosis change the problem?

Second, I would like to ask a little about the evolution of your reported change in anastomotic technique. You had many opportunities over a long period of time. What finally led to the stapled approach?

Third, I am a little concerned about the 3 patients who experienced gastric tip necrosis. In your manuscript there was a reduced percentage of this complication before the use of the stapler. In some way did the change in the anastomotic technique cause this increased gastric tip necrosis problem?

I would like to thank you again for an excellent presentation and your continued honesty and attempts at improving this operation. From your efforts, we all learn.

Dr Orringer. Thank you, Dr Trastek. Why the higher leak rate in the neck? There are several reported laboratory studies that have demonstrated impaired blood flow in the mobilized stomach. Measured tissue oxygen level in the tip of the stomach declines with each progressive step of gastric mobilization: dividing the short gastric vessels, dividing the left gastric artery, and then bringing the stomach to the neck. Each step produces some degree of relative gastric ischemia, but because of its 4-vessel blood supply, the stomach fortunately survives on its submucosal collateral circulation, which becomes progressively more established with time and is generally efficient for anastomotic healing. So the more we pull that relatively ischemic stomach to the neck, the more we harm an organ whose blood supply has been at least temporarily damaged. And that, I believe, is the reason that the leak rate in the neck has been higher than that reported with an intrathoracic esophageal anastomosis.

How did we change? Why did we change? Our incidence of leak after a CEGA consistently remained between $10 \%$ and $15 \%$ whether we tried double-layer, single-layer, interrupted, 
or running techniques. We soon learned that this relatively easy problem to handle in the acute postoperative period had major long-term implications. An anastomotic stricture developed in $50 \%$ of patients. A cervical esophageal stricture is an awful problem with which to deal. We can teach people to swallow esophageal dilators at home, and they are grateful that they can eat, but having to be a "sword swallower" the rest of one's life is not exactly a stellar outcome of such surgery.

Until recently, we were afraid to discharge patients after THE until their 10-day barium swallow examination showed no leak. This was our gold standard because so few people $(<1 \%)$ would leak after 10 days. We are much more secure now with earlier discharge, given our experience with the Endo GIA 3-staple line anastomosis.

We have also learned the importance of keeping trauma to the stomach at an absolute minimum. The goal is to have as healthy and pink a stomach in the neck available for the anastomosis as in the abdomen. The gastric tip ecchymosis that we formerly encountered when we tacked the stomach to the prevertebral fascia with suspension sutures or sutured a drain to the stomach to draw it through the mediastinum is not there anymore because we avoid this gastric trauma.

Therefore the rationale as to why we changed to a stapled anastomosis has to do with our frustration and dissatisfaction with a leak rate that seemed absolutely stable after every attempt to alter our manual techniques, as well as the good luck we had with this stapler in the repair of esophageal perforations.
As Dr Trastek has pointed out, 3 of our patients had varying degrees of gastric tip necrosis after having their anastomoses stapled. Gastric tip necrosis is a random event that can occur after a CEGA or, I should say, after mobilizing the stomach to the neck. It is clear that gastric tip necrosis can occur without anastomotic disruption, as was the case in 2 of our patients; the anastomoses were intact.

One of these patients was very obese and was found at reexploration to have compression of his stomach at the diaphragmatic hiatus. This compromised his right gastroepiploic vessels at this level and resulted in ischemia of the entire intrathoracic stomach that was not a function of his stapled cervical anastomosis. The second patient was also obese and had ischemic necrosis of the stomach above the clavicles with an intact anastomosis. The third patient had been treated at another hospital with large doses of radiation therapy and chemotherapy, and at the time of the THE, we were concerned that we were not bringing a normal stomach up into the neck.

Suffice it to say that I think one of the important technical points with this anastomosis is that in applying that stapler to the esophagus and stomach, one must be very careful to rotate the lesser curvature gastric suture line well to the patient's right so that the anastomotic staple line and the gastric staple suture line do not intersect. If they are too close, there can be intervening necrosis of the gastric wall with subsequent major anastomotic problems.

\section{Timely}

The Journal of Thoracic and Cardiovascular Surgery delivers the information you need now. Articles usually appear within four months of acceptance. 